\title{
Ecologically safe methods of treatment of wastewater from zinc and nickel ions with complex sorbents
}

\author{
Ihor Petrushka ${ }^{1}$, Volodymyr Mokryi ${ }^{2}$,Kateryna Petrushka ${ }^{3}$
}

1. Department of Ecological Safety and Nature Protection Activity, Lviv Polytechnic National University, UKRAINE, Lviv, 2/4 Karpinskoho Street, Building 1, E-mail: ihor.m.petrushka@lpnu.ua

2. Department of Ecological Safety and Nature Protection Activity, Lviv Polytechnic National University, UKRAINE, Lviv, 2/4 Karpinskoho Street, Building 1, E-mail: volodymyr.i.mokriy@lpnu.ua

3. Department of Chemical Engineering, Lviv Polytechnic National University, UKRAINE, Lviv, 9 Yura square Street, Building 9, E-mail: kateryna.i.petrushka@lpnu.ua

Abstract - Sorption properties of natural and complex sorbents for neutralization of $\mathrm{Ni}^{2+}$ and $\mathrm{Zn}^{2+}$ ions from aqueous medium are investigated. The isotherm of adsorption of $\mathrm{Ni}^{2+}$ and $\mathrm{Zn}^{2+}$ ions was built on complex sorbents in accordance with the Langmuir and Freundlich models, the type of adsorption isotherms according to the classification of S. Brunauer was established.

Keywords - adsorption, adsorbents, isothermal adsorptions, nickel, zinc.

\section{Introduction}

One of the main tasks of environmental protection is the prevention of ingress into wastewater, the ground cover of components that contain heavy metal ions in concentrations higher than the permissible ones. Heavy metal ions have an extremely negative effect on living organisms, because they have cumulative and toxic properties, make it difficult for natural and wastewater treatment plants to operate.

Today, according to experts, with insufficiently treated industrial wastewater in natural water bodies annually get thousands of tons of highly toxic heavy metals, such as zinc - 3.3 thousand tons, nickel - 2.4 thousand tons, chromium - 0.5 thousand tons and others, significantly complicating the environmental situation in the country. The main sources of these components are usually industrial facilities with a developed industrial base and a wide range of technological processes and operations, including the aviation industry, which uses the latest methods of materials processing, introduces advanced technologies and more. However, we should not forget about the extent of pollution of the environment with heavy metal ions thrown in the landfill spent batteries.

The most well-known and widespread "finger" batteries contain a lot of manganese and zinc (23-28\% is contained in lead salt batteries), a little less - some other heavy metals and chemical elements.

Approximately 2,500 tons of batteries are imported to Ukraine annually, but only $1 \%$ of them are going for recycling. The battery thrown by us on garbage gets to a landfill of household waste. There, as a result of various organic reactions and corrosion, harmful chemical compounds from batteries get directly into the environment: they pollute water bodies, soil, and get into food chains due to plants.

Numerous scientific publications of domestic and foreign scientists are devoted to the removal of zinc and nickel ions from solutions and the study of the mechanism of the sorption process [1-2].

It is known that the most promising method of wastewater treatment is sorption technology, which is widely used in various industries. Currently, considerable experience has been gained in the use of natural clay minerals and their modified forms for wastewater treatment from heavy metal ions. 
The prospect of using natural minerals in the process of effluent purification is confirmed not only by their high adsorption capacity, but also by the existence of effective methods for improving the adsorption properties of minerals and the nature of their surface by modification.

However, given the high selectivity of natural minerals, a significant number of scientists are working to improve the sorption properties of natural minerals by modifying them, or using the selectivity of mineral sorbents and integrated use.

In addition to traditional natural sorbents (clinoptilolite, palligorskite, glauconite), which are used to treat waste water from heavy metal ions, shungite rocks are no less interesting mineral in sorption ability.

Shungite rocks are unique in composition, structure and properties. They are an unusual natural composite structure - uniform distribution of highly dispersed crystalline silicate particles in an amorphous carbon matrix. The average size of silicate particles is about $1 \mu \mathrm{m}$. The average rock composition of the deposit is $30 \%$ carbon and $70 \%$ silicates. Rocks are characterized by high strength, density, chemical resistance and electrical conductivity. They have a number of unusual physical, chemical, physicochemical and technological properties.

The bulk (up to 99\%) of shungite is represented by non-crystalline carbon, the defining feature of which is the globular structure. It is based on a ball - a hollow multilayer formation with sizes up to $10 \mathrm{~nm}$. This noticeable curvature of the graphite layers allowed the authors to draw a conclusion about the fullerene-like structure of shungite carbon. Mineral components are represented by fine (from 1 to $10 \mathrm{mkm}$ ) crystals of mica, quartz, albite, and others. This structure allows us to consider shungite as a natural composite material and provides for the possibility of their unique sorption properties.

An important task in studying the sorption properties of sorbents is the process of modeling and predicting the mechanism of absorption of pollutants from liquid media.

Therefore, studies aimed at reducing the anthropogenic load on the environment by improving the adsorption properties of sorbents in wastewater treatment from used batteries containing mercury, cadmium, lead, tin, nickel, zinc, magnesium and others are relevant and important for improving the environmental safety of water environment.

\section{Conclusion}

Based on experimental studies, the adsorption isotherms of $\mathrm{Ni}^{2+}$ and $\mathrm{Zn}^{2+}$ ions on complex sorbents according to the Langmuir and Freundlich models were obtained, and their type was determined according to the classification of $\mathrm{S}$. Brunauer. The value of the maximum sorption capacity $\mathrm{G}_{\max }$ of sorbents relative to $\mathrm{Ni}^{2+}$ and $\mathrm{Zn}^{2+}$ ions was established. Optimal ratios, "solid liquid" to achieve maximum absorption.

\section{References}

[1] Bolshanina, S. B., Vorobiova, I. H., Hlovyn, N. M., \& Malovanyy, M. (2013). Doslidzhennia zdatnosti hlynystykh sorbentiv do adsorbtsii ioniv tsynku. Visnyk KrNU im. M.Ostrohradskoho, 3/2013(80), 203-206.

[2] Yang, K., Yan, L., \& Yang, Y. (2014). Adsorptive removal of phosphate by Mg-Al and ZnAl layered double hydroxides: Kinetics, isotherms and mechanisms. Sep. Purif. Technol., (124), 36-42.

[3] Zhang, C., Gu, P., Zhao, J., Dhang, Z., \& Deng, Y. (2009). Research on the treatment of liquid waste containing cesium by an adsorption-microfiltration process with potassium zinc hexacyanoferrate. J. Hazard. Mater., (167), 1057-1062. 